
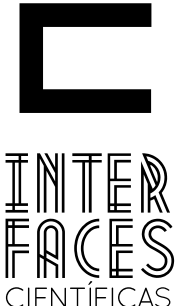

HUMANASE SOCIAIS

\title{
UM BREVE ENSAIO DA PSICOLOGIA ACERCA DO COMPORTAMENTO CONSUMISTA NA SOCIEDADE ATUAL
}

Matheus Batalha Moreira Nery ${ }^{1}$ Thallita Katiussia Santana Torres

\section{RESUMO}

Na sociedade contemporânea o consumo vem sendo visto como uma atividade complexa e o pensamento sociológico e psicológico sobre ele apresentam diversos caminhos para a investigação. 0 presente artigo tem o objetivo de discutir algumas das diversas relações entre consumo, cultura e sociedade, por meio de uma reflexão sobre a dimensão individual e social do consumo bem como o consumo como transtorno compulsivo. Para tanto, várias perspectivas conceituais serão utilizadas de forma a apresentar um quadro ampliado das discussões sobre o assunto na psicologia, sociologia, antropologia e, a partir dessa contextualização mais vasta, alcançar uma possível categorização das dimensões sociais do consumo, de suas características e das maneiras pelas quais elas são vividas na sociedade.

\section{PALAVRAS-CHAVE}

Consumo. Sociedade. Psicologia.
Carla Adelle Santos Menêses

\section{ABSTRACT}

Consumption in the contemporary society has been seen as a complex activity, and the psychological and sociological thinking about it has been intensively researched. This paper aims to discuss some of the various relationships between consumption, culture and society, through a reflection on the individual and the social dimension of consumption and consumption as compulsive disorder, as well. In order to achieve this goal, many conceptual perspectives will be used, in order to present a broad picture of the discussions on the subject in psychology, sociology, anthropology, and, from this broader context, one can categorize the social dimensions of consumption, their characteristics and the ways in which they are seen in society.

\section{KEYWORDS}

Consumption. Society. Psychology. 


\section{RESUMEN}

En la sociedad contemporánea el consumo ha sido visto como una actividad compleja y el pensamiento sociológico y psicológico sobre él presenta diversas formas de investigación. Este artículo pretende analizar algunas de la diversas relaciones entre el consumo, la cultura y la sociedad a través de una reflexión sobre la dimensión individual y social, así como el consumo como trastorno compulsivo. Por tanto, se utilizarán diversas perspectivas conceptuales con el fin de presentar un marco más am- plio de los debates sobre el tema en el marco de la psicología, la sociología, la antropología, y a partir de una mayor contextualización, lograr una posible categorización de las dimensiones del consumo, sus características y el modo como éstos son experimentados en la sociedad.

\section{PALABRAS CLAVE}

Consumo. Sociedad. Psicología.

\section{INTRODUÇÃO}

0 consumo, que pode ser compreendido como o ato ou o efeito de consumir, é um elemento de sobrevivência biológica, embora faça parte ativamente do psicológico das pessoas e se situe entre as mais básicas e remotas atividades do ser humano (BAUMAN, 2008)

É possível viver sem produzir, mas viver sem consumir mostra-se uma situação bastante difícil uma vez que o ser humano depende do consumo para garantir sua sobrevivência (BARBOSA, 2006). Atividade caracteristicamente individual, em algumas situações se dá de forma pública - como no consumo dos serviços de transporte e saúde, por exemplo - e pode ter também um aspecto de esgotamento de recursos: "Consumo se divide entre uma atividade de suprimento e outra de dispêndio, numa referência tanto àquilo que nutre e alimenta quanto àquilo que exaure e destrói” (CYPRIANO, 2008, p. 10).

Uma das distinções analíticas importantes, nesse sentido, é a que se estabelece entre "consumo" e "consumismo" e que nos auxilia a compreender as mudanças da importância do consumo para os indivíduos e de seu papel na vida social: parte-se, assim, de uma perspectiva individualista - 0 ato de consumir - para uma perspectiva social - a de uma sociedade que se constitui tendo o consumo como papel determinante na organização de sua vida social (SENNETT, 2006). Desde o início do século XVII, temas como individualismo, materialismo, hedonismo, lassidão moral, dentre outros de igual conotação valorativa negativa, foram associados ao consumo: "Observadores modernos usaram uma linguagem dramática equivalente, referindo-se ao consumo como uma "orgia do gasto" [Mc Kendrick et al. ] ou como a criação de um mundo de sonho [Williams]" (MCCRACKEN, 2003, p. 21).

Isso não acontece em todos os países de forma generalizada. É de cerca de um bilhão e setecentos milhões de adeptos os constituintes desta "classe consumista" sendo a metade deles nos países em desenvolvimento. É uma cultura e estilo de vida que se tornaram comuns na Europa, América do Norte e Japão e alguns outros bolsões do planeta no século $X X$ e que se globalizam até o século XXI (WORLDWATCH INSTITUTE, 2004).

A base para uma alienação social mais profunda, resultante dos fetiches das mercadorias, era a aliena- 
ção dos consumidores com relação ao que consomem (Karl Marx). Outros autores marxistas, em especial os Frankfurtanos, estabeleceram uma relação direta entre consumo e alienação, especialmente no que tange ao consumo de massas: foi o caso de grande parte dos estudos de Theodor Adorno, Max Horkheimer e Herbert Marcus. Outros autores clássicos no pensamento sociológico, como Max Weber, Émile Durkheim e Walter Benjamin, também evidenciaram esse perfil negativo do consumo.

Essa visão que durante muito tempo predominou na compreensão sobre o consumo revela o grau de ingenuidade e idealização com que o ocidente visualizava a sociedade, encarando as relações sociais de forma desassociada das relações materiais. Nesta concepção, a importância dos bens para as pessoas se daria apenas nos campos da ostentação e diferenciação social, numa visão que, segundo Campbell, se perpetuava desde há muito tempo:

\begin{abstract}
Consumir e utilizar elementos da cultura material como elemento de construção e afirmação de identidades, diferenciação e exclusão social são universais. 0 apego a bens materiais não é uma característica da sociedade contemporânea nem daqueles que possuem materialmente muito. Ambos os elementos estão e já estiveram presentes de forma intensa em outras sociedades e segmentos sociais. (CAMPBELL, 2006, p. 35-36).
\end{abstract}

Atualmente, os modelos de produção mudaram muito. 0 trabalho é uma plataforma para o consumo, pois as pessoas se organizam para consumir, e o acesso aos bens de consumo causa um impacto no modo como as pessoas pensam e comportam-se.

Na década de 1980, essa postura sofreu uma alteração e o tema consumo passou a despertar o interesse dos cientistas sociais. A comunidade reconheceu, nesse momento, na esteira do pensamento de Braudel e de McKendrick, que a "grande transformação" do Ocidente se constituiu não apenas a partir de uma "revolução industrial", mas também uma "revolução do consumo" que transformou radicalmente o mundo ocidental.
O consumo moderno foi a causa e a consequência de tantas mudanças sociais e sua emergência marcou nada menos que a transformação do mundo ocidental. Como sugeriu um historiador, o aparecimento da "revolução do consumo" rivaliza apenas com a revolução neolítica no que toca à profundidade com que ambas mudaram a sociedade (MCCRACKEN, 2003).

Essa revolução do consumo significou não somente a modificação nos gostos, hábitos e preferências de compras, mas também uma fundamental remodelação na cultura mundial da modernidade: alteraram-se os conceitos de tempo, espaço, sociedade, indivíduo, família e Estado. Em consequência, o campo de investigação do consumo se tornou demasiado complexo, englobando diversas atividades, atores e um conjunto de bens e serviços que não se restringem necessariamente aos providos sob a forma de mercadorias, embora a maioria dos autores tenda a focalizar em suas análises apenas as coisas adquiridas no mercado (BARBOSA; CAMPBELL, 2006).

O que mudou na análise do consumo foi, principalmente, o entendimento de que este não é apenas uma função de suprimento e dispêndio - como se observa na visão utilitarista de que se consome apenas em função das necessidades ou de que a sociedade produz os bens de consumo e estes precisam ser consumidos. A ampliação do conceito de necessidades, especialmente com as categorias de distinção entre consumo básico e supérfluo e o rompimento com a visão economicista centrada na produção e no consumo individual para o suprimento de necessidades, trouxeram à tona a importância de se debruçar sobre o consumo em busca de seus aspectos culturais e seu papel na estrutura social.

No capitalismo de consumo, o lucro passa a se dar mais pelo volume de vendas do que pelo preço unitário dos produtos, o qual tem agora uma margem de ganho menor. Essa primeira fase de seu desenvolvimento cumpriu as primeiras condições para se dar semelhante dinâmica, pois "inventou o marketing de 
massa, bem como o consumidor moderno" (p. 28). Além disso, criou a marca - o nome dos produtos - e também os grandes magazines. Esses últimos foram responsáveis por um extraordinário aumento no volume das vendas e, principalmente, por dar glamour ao consumo com as técnicas que inauguraram o "consumo-sedução" e o "consumo-distração" que perduram até hoje (LIPOVETSKY, 2007).

A segunda fase do capitalismo de consumo inicia-se por volta de 1950 e desenvolve-se principalmente durante as três décadas seguintes. Trata-se de um período de grande desenvolvimento econômico, coincidente com a "sociedade de abundância" e o consumo de massa propriamente dito. No que toca ao sistema de crédito, é difundido e há uma revolução comercial caracterizada pela super competitividade dos preços. 0 modelo "Taylor-fordista" é apontado pelo autor como o grande responsável tanto pela otimização da produção - diminuição do tempo e custo da mesma ao mesmo tempo em que aumenta seu volume - quanto pelo incremento da produtividade dos trabalhadores industriais e progressão dos salários. Com a ampliação do poder de compra dessa classe social, passou a ser acessível à massa "uma demanda mais individualizada, um modo de vida (bens duráveis, lazeres, férias, modas) antigamente associado às elites sociais" (LIPOVETSKY, 2007).

Ainda na segunda fase, emergem as políticas de diversificação dos produtos bem como processos visando reduzir o tempo de vida das mercadorias. A lógica é a da moda; o imperativo é renovar sempre e com rapidez em busca de um hedonismo centrado em satisfações imediatas. 0 individualismo exacerba-se e, consequentemente, há um desinvestimento nos ideais e nas causas coletivas. 0 consumo, entretanto, ainda é, na fase II, mais do tipo "para o outro" no sentido de que os objetos de consumo são adquiridos no afã de se obter prestígio e diferenciação social - os quais deverão ser apreciados/invejados pelos demais (BAUDRILLARD, 1995).
A fase III do capitalismo de consumo - iniciada a partir das últimas décadas do século XX - inaugura o "consumo emocional", marcado pela hiperindividualização da demanda e destinado a propiciar, sobretudo, "experiências afetivas, imaginárias e sensórias" com a proliferação desenfreada de produtos cuja obsolescência é programada já em sua fabricação. A partir desse momento, as motivações individuais e a busca por novas e prazerosas sensações suplantam o desejo de ostentar símbolos de superioridade econômica. A função do consumo atinge um nível mais profundo: o que está principalmente em questão para o consumidor agora é a tentativa de encontrar a si próprio, o que acabará equiparando-o ao nível da mercadoria: "Numa época em que as tradições, a religião, a política são menos produtoras de identidade central, o consumo encarrega-se cada vez melhor de uma nova função identitária" (p. 44). A relação com as mercadorias adquire um novo significado na fase do consumo emocional: por meio delas, o hiperconsumidor logo irá conferir um sentido, muito embora superficial, ao mundo que o rodeia e à sua própria existência (BAUDRILLARD, 1995).

O chamado "culto das marcas", que diz respeito ao glamour e à exaltação das mesmas pelos consumidores, tem um importante sentido nesse tipo de sociedade, pois perfaz a busca de 'segurança' subjacente a ansiedades específicas do homem contemporâneo. As tradições e os referenciais das culturas de classe se encontram em ampla dissolução com o acesso da massa ao consumo e o desaparecimento das formas de socialização que, no passado, "distinguiam inequivocamente o alto e o baixo, o bom gosto e o mau gosto, a elegância e a vulgaridade, o chique e o popular". Em consequência, o consumidor, temeroso, confuso e ansioso, recorre às pretensas garantias de autenticidade, bom gosto e condições sanitárias que as marcas logram representar (LIPOVESTKY, 2007). 


\section{SOCIEDADE DE CONSUMO}

Com a criação e aplicação dos maquinários a vapor, por volta do ano de 1750 , a conhecida Revolução Industrial tomou forma e proporcionou ao homem uma multiplicação cada vez maior e mais rápida dos objetos. Tal acontecimento pode ser considerado com sendo um dos pilares de apoio do que se convêm chamar de Sociedade de Consumo. Esta determina e controla, de forma direta, os métodos de consumo, de trabalho, até poder moldar, de certa forma, a personalidade do individuo que se encontra inserido neste tipo de sociedade. No entanto, o consumo existe desde os primórdios da humanidade.

Diferentemente de Consumo, que é uma característica e uma ocupação dos seres humanos como indivíduos, o Consumismo é um atributo da Sociedade. Para isso, é preciso que as pessoas tenham a capacidade de querer, desejar, almejar, da mesma forma que tinham a aptidão do trabalho na sociedade de produtores; "destacada", "alienada" dos indivíduos e reciclada numa força externa que coloca a "sociedade de consumidores" em movimento e a mantém em continuidade como uma forma específica de convívio humano, enquanto ao mesmo tempo estabelece parâmetros para as estratégias individuais de vida que são eficazes e manipula as probabilidades de escolha e conduta individuais (BAUMAN, 2011).

Uma característica muito evidente da Sociedade de Consumo é o uso do financiamento. 0 consumidor adquire o objeto desejado agora, em troca de seu futuro trabalho, de algo que ainda nem possui e que é incerto. Também é característico o controle de mercado, no qual é criada uma demanda de consumo. Temos, então, a inversão do ciclo de venda: onde o consumo controlava a produção, agora temos a produção que controla o consumo.
Esse tipo de sociedade tem como base a promessa de satisfação dos desejos imediatos em um nível inalcançável em comparação com as sociedades do passado, ou mesmo sonhar, mas a promessa de satisfação só permanece sedutora enquanto o desejo continua insatisfeito. É mais importante ainda quando o cliente está plenamente satisfeito, ou seja, enquanto não se acredita que os desejos que motivaram e colocaram em movimento a busca da satisfação e estimularam experimentos consumistas tenham sido verdadeira e totalmente realizados.

A publicidade, outra importante característica da Sociedade de Consumo, é um método mais do que eficaz de controle e de manipulação do ato de compra, podendo ser encontrada em praticamente todos os lugares. E todo o custo de cartazes, pôsteres, filmes publicitários, entre outros, acaba recaindo justamente no preço final do produto, ou seja, o consumidor acaba por financiar o sistema que controla as suas "pseudo-escolhas-livres". 0 uso "novo" é sabiamente utilizado pela publicidade e empresas e ilude o consumidor com a ideia do "novo" que destrona o "velho", mesmo que este novo tenha mudado (ou não) um aspecto de pouca importância. Além disto, o "novo" se sobrepõe cada vez mais rápido, gerando situações em que o que é "novo" agora, pode não ser mais "novo" daqui a dois dias. A moda aparece então como sendo os "novos" métodos de conduta adotados por indivíduos das classes "elevadas", e que são imitados e copiados pelos menos abastados para se sentirem mais próximos das "elites". 


\section{CONSUMIDORES COMPULSIVOS}

A concepção de que as pessoas tomam suas decisões de compra pautadas apenas em critérios racionais ou avaliações cognitivas das opções de mercado tem perdido espaço para correntes que pregam que as relações de compra são bastante influenciadas pela ótica comportamental (DITTMAR, 2005). A explicação acerca do processo de consumo relacionada às variações entre oferta demanda e o consumidor racional tem sido substituída pela influência dos pensamentos, das atitudes, das expectativas e dos sentimentos intrínsecos a esse decurso (FERREIRA, 2008). 0 comportamento de compra compulsiva tem sido um assunto bastante discutido em artigos de inúmeros periódicos ao redor do mundo. Foi reportada a existência de trabalhos científicos acerca da compra compulsiva em Israel (SHOHAM; BRENCIC, 2003), Estados Unidos (NORUM, 2008), Alemanha (NEUMER; RAAB; REISCH, 2005), Brasil (TAVARES et. al. , 2008), Coréia do Sul (PARK; BURNS, 2005), Chile (ARAVENA et. al. , 2006), Canadá (LEE; MYSYC, 2004), Austrália (PHAU; WOO, 2008) e norte da Europa (SARANEVA; SAAKSJA, 2008).

Um dos maiores impactos mundiais causados pelo capitalismo foi o consumismo. A troca de produtos que surgiu na pré-história - como forma de organização social - foi se transformando ao longo do tempo e o consumismo tornou-se sinônimo de poder, status, superioridade e não mais uma necessidade básica de sobrevivência. 0 "ter" ficou muito mais importante do que o "ser" e o ato de comprar deixou de ser necessidade e se transformou numa fonte de prazer para as pessoas, um prazer que, quando em excesso, caracteriza um desequilíbrio psicológico denominado Oniomania (GIGLIO, 2005).

A classificação da compra compulsiva continua incerta. Não há consenso entre os pesquisadores e nenhuma referência oficial nos principais manuais nosológicos (TAVARES, 2008). As patologias relacio- nadas a distúrbios compulsivos foram observadas no início do século XIX, porém estudos mais incisivos sobre 0 assunto surgiram apenas no fim da década de 1980 (MAGGE, 1994). O’Guinn e Faber (1989) foram os primeiros a identificar e delimitar o conceito de compra compulsiva como crônica e repetitiva que se torna uma resposta primária a eventos ou sentimentos negativos. Outros autores, a exemplo de Neumer, Raab e Resisch (2003) afirmam que a compra compulsiva tem o objetivo, mesmo que inconsciente, de satisfazer as necessidades físicas através da expressão de uma identidade pessoal, regular a ansiedade ou simplesmente satisfazer anseios relacionados a status social. Após o processo de compra, os sentimentos mais comuns entre os portadores do transtorno são de culpa, arrependimento, ansiedade, vergonha, que podem evoluir para um quadro de depressão grave e tendências suicidas (FERREIRA, 2008). Como consequência desse comportamento, pode-se destacar os altos índices de endividamento, a baixa autoestima, problemas legais e dificuldades conjugais, além do afastamento social e familiar (O'GUINN; FABER, 1989). É pertinente observar que os termos compra compulsiva, compra impulsiva e consumo compulsivo não são sinônimos, apesar de se relacionarem (VELUDO-DE-OLIVEIRA; IKEDA; SANTOS, 2004).

O comportamento de compra compulsiva advém de uma vontade avassaladora, incontrolável, crônica e repetitiva de comprar simplesmente com o intuito de amenizar os sentimentos de estresse e ansiedade. Não existe, portanto, um foco no produto, e sim no prazer e alívio das sensações negativas proporcionadas pelo ato de comprar. Diferentemente da compra compulsiva, que é patológica, a compra impulsiva é caracterizada por uma vontade repentina e espontânea de adquirir um objeto específico, que tem um significado simbólico para o indivíduo (EDWARDS, 1993). Há, portanto, uma relação hedônica entre o consumidor e o produto (ARAVENA, 2006). Nesse tipo 
de comportamento há uma resposta específica motivada, geralmente, por apelos publicitários ou por outras ferramentas do composto mercadológico (PINTO, 2003).

É preocupante a compulsão na compra, pois está conceitualmente conectada a outras compulsões como, por exemplo: alcoolismo, uso de drogas, desordens ligadas á alimentação e compulsão por jogo. Compradores compulsivos, quando comparados com outros consumidores, possuem: baixa autoestima, grande tendência à fantasia, alto nível de depressão e altos níveis de reações de ansiedade e obsessão. Além

\section{ONIOMANIA/TRANSTORNO DE COMPRAR COMPULSIVO}

Oniomania - do grego onios, à venda, e mania, insanidade - é o termo técnico para o desejo compulsivo de comprar, mais comumente conhecido como síndrome do comprar compulsivo. 0 termo foi inicialmente utilizado por Kraepelin em 1915 e Bleuler em 1924. Embora tenha sido descrita há mais de cem anos, só nos últimos 15 anos a doença voltou a ser estudada, o que faz com que seja virtualmente desconhecida nas discussões sobre saúde mental.

Também chamado de Transtorno do Comprar Compulsivo (TCC), atinge $5 \%$ da população mundial segundo estimativas da Organização Mundial de Saúde (OMS). Uma a cada vinte pessoas sofre do mal que desestrutura famílias, separa casais, causa desemprego e leva cada vez mais brasileiros aos consultórios de psicologia e psiquiatria.

A doença é silenciosa, solitária, sorrateira. Instala-se na vida das pessoas independentemente de idade, sexo ou classe social. As mulheres são mais vulneráveis e também corajosas para admitir que disso, a motivação para compra compulsiva parece servir mais como uma tentativa de atingir objetivos interpessoais e de alta estima do que um forte desejo de possuir coisas (O'GUINN; FABER, 1989).

Os critérios para o consumismo podem ser racionais, emocionais, sofrendo influências sociais e culturais, dependendo do consumidor e do grau de importância do produto que ele deseja adquirir (SCHIFFMAN; KANUK, 2009). O consumo é objeto de uma preocupação que engloba uma série de problemas, tanto de fundo psicológico quanto de fundo econômico e social.

estão doentes e precisam de ajuda, mas a vergonha ainda afasta o oniomaníaco dos tratamentos que são feitos com terapias em grupo, psicoterapia e, em alguns casos, associados a medicamentos. É importante ressaltar que pode haver comorbidade com o Transtorno do Comprar Compulsivo (TCC) e, portanto, a presença de sintomas como depressão, ansiedade, rejeição, devem ser tratados paralelamente à compulsão por comprar. Os profissionais da área são taxativos em que, assim como em relação ao álcool e às drogas, o compulsivo deve ficar sempre vigilante para evitar as recaídas.

O “vício" em compras está entre as dependências mais comuns do século XXI embora ainda não seja uma patologia reconhecida pela medicina e tem como causas a insatisfação, consumismo, materialismo e necessidade de preencher a vida.

Dentre os sintomas dos shopaholics - compradores compulsivos - estão: armários cheios de peças ainda não usadas, dívidas e ocultação das compras das 
pessoas próximas. Ir á centros de compras é um de seus programas prediletos.

O problema se agrava quando a pessoa passa a gastar o dinheiro que deveria destinar à hipoteca, ao seguro do carro ou às compras do mês em sandálias Jimmy Choo ou num vestido Dolce \& Gabbana. Há muito mais pessoas assim do que se imagina e esse vício pode ser tão prejudicial e perigoso quanto o alcoolismo, a dependência química ou o vício em jogos.

É importante distinguir as compras normais daquelas descontroladas. Significativamente, a distinção não é feita com base na quantidade de dinheiro gasto ou no nível de renda, mas na extensão da preocupação, no nível de angústia pessoal e no desenvolvimento de consequências adversas. Muitas pessoas terão orgias de compras ocasionais, particularmente em situações especiais (aniversários, férias), mas o gasto excessivo episódico por si só não se constitui em evidência para confirmar um diagnóstico de Transtorno Compulsivo por compras.

As pessoas portadoras desse transtorno são vítimas de um vazio que só conseguem preencher através do consumo compulsivo. Na maioria das vezes, elas têm problemas de relacionamento com seu parceiro, o que acarreta a necessidade de se verem, a cada dia, de um modo diferente, sempre buscando a perfeição. Esse cenário leva a um problema muito mais profundo, o da insegurança. Os viciados se enganam dizendo frases do tipo "Não posso deixar de aproveitar esta "pechincha" ou "Este é o vestido da minha vida". Porém, não se dão conta do que realmente precisam e usam o cartão de crédito para se sentirem bem.

Não há tratamento padrão para o transtorno, porém há vários estudos de caso com relação ao tratamento de compradores compulsivos, cada um deles enfatizando a importância das experiências iniciais da vida. Mais recentemente foram desenvolvidos modelos cognitivo-comportamentais para o transtorno de comprar compulsivo a exemplo da exposição a estímulos e prevenção de respostas. Através desse estudo, Bernik relatou o caso de dois pacientes com transtorno de pânico e agorafobia comórbidos e que eram responsivos a clomipramina. No entanto, compras descontroladas dificultaram a resposta à droga. Ambos os pacientes responderam bem a 3-4 semanas de exposição a estímulos e prevenção de respostas ainda que não tenha sido apresentado nenhum relato do acompanhamento posterior (LEJOYEUX, 1997).

\section{CONCLUSÃO}

Apenas a partir da década de 1980, o consumo tornou-se uma das problemáticas obrigatórias das ciências sociais. Desde então, ocorreu a disseminação das pressuposições teóricas da centralidade do consumo nos processos de reprodução social e da caracterização da sociedade moderna como uma "sociedade de consumo".

Este artigo buscou sistematizar uma produção extensa e de grande complexidade atinente a um tema complexo que remete a diversas áreas do saber, sobretudo à sociologia e à psicologia, cujas reflexões acerca da questão do consumismo e suas dimensões sociais e individuais ainda são recentes.

Para tal desenvolvimento foi necessário adotar uma postura transversal - atenta às dimensões simbólicas e sociais que atravessam o consumo e ciente do fato de que o consumo desliza em múltiplas direções na vida social, envolvendo uma série de atores - e tomar como referências um grande número de autores e de abordagens relativos aos diversos significados do consumo à luz de diferentes teorias sociais. 
É de grande importância que se destine estudos e pesquisas com essa temática para maior compreensão das relações dos indivíduos com o consumo bem como para maiores informações sobre o transtorno de comprar compulsivo e como tratá-lo. É necessário voltar-se para pesquisas dedicadas á investigação detalhada das

\section{REFERÊNCIAS}

BAUDRILLARD, J. A sociedade de consumo. Lisboa: Edições 70, 1995.

BAUMAN, Z. 0 Mal-estar na Pós-modernidade. Rio de Janeiro: Jorge Zahar, 1998.

BAUMAN, Z. Vida para consumo: a transformação das pessoas em mercadorias. Trad. Carlos Alberto Medeiros. Rio de Janeiro: Jorge Zahar Ed. , 2008.

BARBOSA, L. ; CAMPBELL, C. O estudo do consumo nas ciências sociais contemporâneas. In: BARBOSA, L.; CAMPBELL, C. (Org. ). Cultura, consumo e identidade. Rio de Janeiro: Editora FGV, 2006, p. 21-44.

CAMPBELL, C. Eu compro, logo sei que existo: as bases metafísicas do consumo moderno. In BARBOSA, Lívia; CAMPBELL, C. (Org. ). Cultura, consumo e identidade. Rio de Janeiro: Ed. FGV, 2006.

CYPRIANO, C. P. Nada tão fútil que não possa dizê-lo útil: a atividade de consumo na experiência contemporânea. 2008. (Dissertação de Mestrado em Sociologia) - Faculdade de Filosofia e Ciências Humanas, Universidade Federal de Minas Gerais, Belo Horizonte, 2008.

Compras compulsivas: uma revisão e um relato de caso. Rev. Bras. Psiquiatr. [online]. 2008, v. 30, supl. 1, p. S16-S23. dimensões do consumo na vida social aqui apontadas - e talvez com o acréscimo de outras -, uma vez que se mostra, de forma inconteste, que qualquer pretensão de compreensão, empiricamente fundamentada, de nossa atual condição cultural, deve, inevitavelmente, passar por essa noção: o consumo.

GADE, C. . Psicologia do Consumidor e da Propaganda. Edição revista e ampliada. São Paulo: EPU - Editora Pedagógica e Universitária LTDA.

LIPOVETSKY, G. A felicidade paradoxal: ensaios sobre a sociedade de hiperconsumo. Trad. Maria Lúcia Machado. São Paulo: Companhia das Letras, 2007.

MARX, K. O capital. São Paulo: Abril Cultural, 1983.

SCHIFFMAN, L. G. ; KANUK, L. L. Comportamento do consumidor. 6. ed. Rio de Janeiro: Editora LTC, 2000. 476 .

SENNETT, R. A cultura do novo capitalismo. Rio de Janeiro: Record, 2006.

TAVARES, $H$. et al . Compras compulsivas: uma revisão e um relato de caso. Rev. Bras. Psiquiatria, São Paulo, 2008.

Worldwatch Institute. Relatório “0 Estado do Mundo". Instituto Akatu. 2004. 
